\title{
DISTRIBUTED LOAD BALANCING OF DISTRICT HEATING SYSTEMS: A SMALL-SCALE EXPERIMENT
}

\author{
Fredrik Wernstedt and Paul Davidsson \\ Department of Systems and Software Engineering, Blekinge Institute of Technology, Ronneby, Sweden \\ Email: fredrik.wernstedt@bth.se,paul.davidsson@bth.se
}

Keywords: Distributed control, Software agents, District heating

\begin{abstract}
We present results from an experiment where the effects of automatic flow control at a single substation is compared to automatic cooperative concurrent flow control at multiple substations. The latter approach is made possible by equipping individual substations with some computing power and integrating them into a communications network. Software agents, whose purpose is to cooperate with other software agents (substations) and to invoke reductions, are connected to each substation. The experiment show that it is possible to automatically load balance a small district heating network using agent technology, e.g., to perform automatic peak clipping and load shifting.
\end{abstract}

\section{INTRODUCTION}

District heating systems are by nature distributed both spatially and with respect to control. Each consumer (substation) can be viewed as a "blackbox" making local decisions without taking into account the global situation. Thus, today a district heating network is basically a collection of autonomous entities trying to optimize operations locally, which typically results in behaviour that is not globally optimal.

ABSINTHE (Agent-based monitoring and control of district heating systems) (WWWABSINTHE) is a collaboration project between Blekinge Institute of Technology and Cetetherm AB. The goal of the project is to improve the monitoring and control of district heating, e.g., by increasing the knowledge about the current and future state of the network at the producer side and by performing automatic load balancing at the customer side. Individual substations are equipped with some computing power and integrated into a cooperative system via a communications network. Each substation is equipped with a software agent (Weiss, 1999, Wooldridge, 2002) that will enable it to cooperate with other substations to perform automatic load control.

A small-scale experiment has been performed in a laboratory accredited by the Swedish Board for Accreditation and Conformity Assessment (WWWSWEDAC) at Cetetherm AB. The objective of the experiment is to validate a decentralized approach to automatically reduce the effect that domestic hot water consumption causes on the primary flow by automatically and concurrently reducing the flow caused by household heating at multiple substations without any central control.

In the next section we discuss the problem domain and motivate a decentralized approach. This is followed by a description of the architecture of the multi-agent system used in the experiment. We then present the results from the experiment. Finally, we conclude and provide pointers to future work.

\section{DISTRICT HEATING SYSTEMS}

Current approaches to operate district heating systems are centralized. The load of a district heating system is mainly a consequence of the customers' demand for household heating. As a result, the operation of most district heating systems is based on a simple mapping between the ambient temperature and the supply temperature. Furthermore, in order to ensure sufficient heat supply, the tendency has been to produce more heat than necessary to satisfy the demands of the consumers (Arvastsson, 2001, Canu et al., 1994, Petersson and Werner, 2003).

A more advanced approach to decide the supply temperature would be to use an optimization model. In a general optimization model the network appears 
as a set of constraints (where consumers have fixed and given demand), and the objective function is composed of cost for production. However, an optimization model of a large district heating system with many loops and more than one heat production plant is extremely computationally demanding (Aringhieri and Malucelli, 2003, Bøhm et al., 2002, Tamminen and Wistbacka, 2001). In fact, it is argued that when the complexity of a district heating system reaches approximately 100 components and restrictions, the present computer and software technology is insufficient to find an optimum operational strategy (Bøhm et al., 2002). Moreover, the actual demand of the consumers is not known. The quality of an optimization model is heavily dependent of the quality of the predictions of future demand (since direct measurements of consumption typically will not suffice as the distribution time is relatively large). Thus, even if we could implement an efficient optimization algorithm, some type of real-time handling of the discrepancies between predicted and actual consumption is needed. Due to the long distribution times, this probably needs to be done in a decentralized manner.

A general argument against centralized approaches for problems as complex as the management of district heating systems is that when the problems are too extensive to be analyzed as a whole, solutions based on local approaches often allow them to be solved more quickly (Rinaldo and Ungar, 1998).

\section{DISTRIBUTED CONTROL OF DISTRICT HEATING SYSTEMS}

It has been suggested that agent technology is a promising approach to manage distributed complex systems (Parunak, 1996), such as district heating systems.

In this work we evaluate a decentralized multiagent system, where individual consumer agents are locally taking interaction decisions. In a decentralized multi-agent system agents interact laterally to achieve coherence. The consumer agents are given two fundamental goals to fulfil: to operate on the behalf of the customers and to coordinate with other agents to perform automatic load balancing.

We assume that the flow of domestic hot water varies in a non-controllable way, i.e., a process disturbance that should be reduced. However, control of domestic hot water consumption would immediately decrease the comfort for the end user, i.e., we should not limit the primary flow caused directly by domestic hot water consumption. However, since the heating of buildings is a slow process, we should be able to make time-limited reductions to the flow caused by radiators without significantly affecting the comfort (Drysdale and Stang, 2002, Österlind, 1982, Gieseler et al 2003).

The consumer agents will impose restrictions to household heating when the consumption levels are raised above specific limits. Each building has its own unique heating characteristic, i.e., the limit for reductions and the persistence of reductions will need to be configured for each individual agent. When enforcing a local reduction the consumer agent also requests reduction assistance from other nearby cooperative substations.

\section{EXPERIMENTAL DESIGN}

\subsection{Laboratory Set-up}

In the experiment we used two heat exchange systems (600 kW and $400 \mathrm{~kW}$ respectively) and one heat producing unit. The substations used were developed by Cetetherm AB during the ABSINTHE project and contain a built-in extendable $\mathrm{I} / \mathrm{O}$ platform with an expansion slot for a communication card (WWW-Siemens). Access to sensor data is provided by a Rainbow communication card (see Figure 2). The $\mathrm{I} / \mathrm{O}$ card contains a database that continuously is updated with sensor data from the I/O channels by a small real-time operating system.

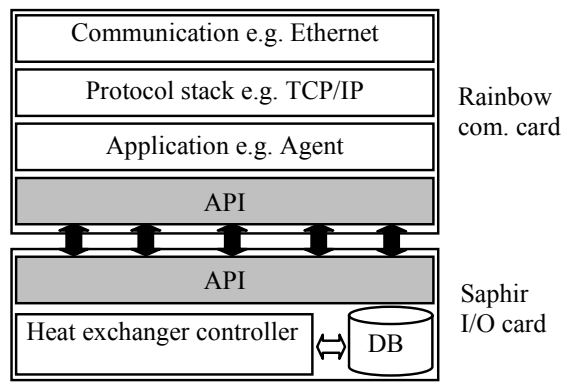

Figure 2: The Rainbow communication and computation card is here shown on top of the Saphir hardware interface card.

A laboratory control computer handled production and consumption as well as making all measurements during the experiments. In Figure 3 we show a conceptual view of the laboratory set-up. 


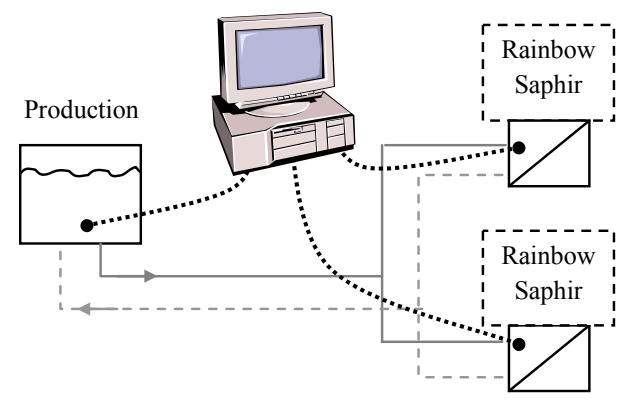

Figure 3: Conceptual view of the set-up with the laboratory control computer.

The consumer agents have the capability to change the temperature set value for the household heating. However, they may maximally reduce it by $15 \%$. A reduction by $15 \%$ may seem small but will actually often result in a temporary shut-down of the heating to the radiator system (since the water returning from the radiator is sufficiently warm). As a result, the consumption will start to decrease immediately, but only at a relatively slow rate.

Another factor that slows down the control is the way that the consumption is measured. We are only able to discover changes in consumption at the same rate as the rate of incoming pulses from the flow gauges. The agents are instead using estimated consumption values over an interval of one minute.

\subsection{Consumption Scenario}

Two substations, $\mathrm{A}$ and $\mathrm{B}$, are set to have a constant radiator demand of approximately $25 \mathrm{~kW}$ and $15 \mathrm{~kW}$ respectively. The system is first allowed to reach a steady state during five minutes. After five minutes Substation B initiates a domestic hot water tapping of $0,2 \mathrm{~kg} / \mathrm{s}$ for a duration of five minutes. The system is then given ten minutes to stabilize. After the stabilization period Substation A initiates a tapping of $0,2 \mathrm{~kg} / \mathrm{s}$, also with a duration of five minutes. After the second tapping the system is given time to stabilize before shutdown.

\section{EXPERIMENTAL RESULTS}

In the approach evaluated consumer agents individually enforce reductions at their substation when the consumption reaches a specific limit. The limit for substation $\mathrm{A}$ is $30 \mathrm{~kW}$ and the limit for substation $\mathrm{B}$ is $20 \mathrm{~kW}$. When a consumer agent enforces a local reduction the agent also requests reduction assistance from the other substation. This approach is evaluated against the normal situation where substations are free to consume the amount requested.

Figure 3 shows the total energy consumption for the case with free consumption and the case with the distributed control strategy during the experiment.

$$
\text { ... No restrictions Decentralized MAS }
$$

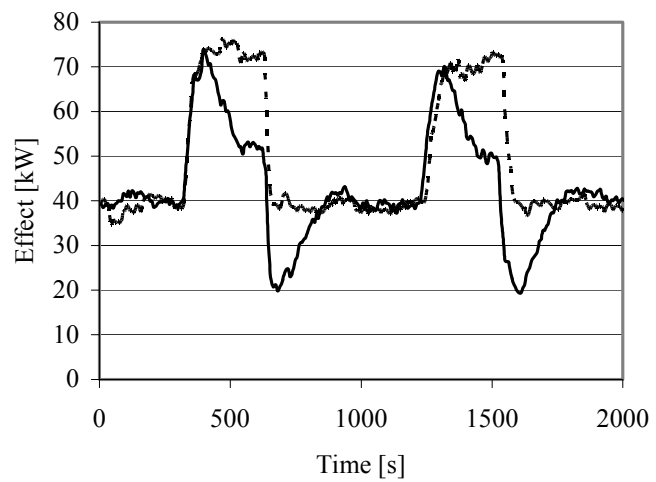

Figure 3: Total energy consumption for the two cases. The desired maximal global consumption is $50 \mathrm{~kW}$.

We see that the strategy to use a decentralized multi-agent based approach clearly reduces the consumption peaks. However, the multi-agent based approach requires some time to assume the stable level after reductions.

Figure 4 shows the amount of time of the total experiment that the consumption has reached and been above effects from $45 \mathrm{~kW}$ to $80 \mathrm{~kW}$, e.g., the agent system had a consumption of $60 \mathrm{~kW}$ and above during $15 \%$ of the duration of the experiment.
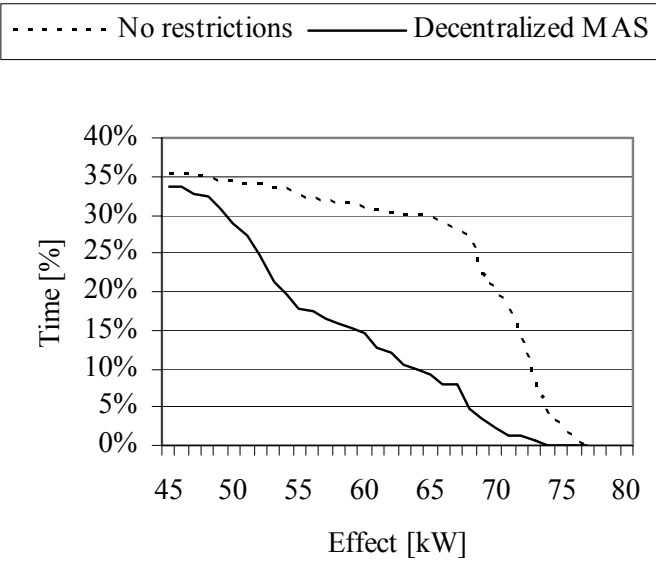

Figure 4: Amount of time of the experiment that the consumption has reached and been above effects from 45 $\mathrm{kW}$ to $80 \mathrm{~kW}$. 
The multi-agent based approach only consumes $63 \mathrm{~kW}$ or more during approximately $10 \%$ of the duration of the experiment. This is contrasted to $30 \%$ for no load balancing at all.

\section{CONCLUSIONS}

We have performed a small-scale experiment in a controlled environment to evaluate the possibility of distributed load balancing in district heating systems. The results show that it is possible to automatically load balance district heating systems without any central control. Other possibilities that integration of substations into a communications network may have, besides environmental and economical are for example the possibility to prioritize certain customers, e.g., hospitals. To our knowledge, agent technology has never been used for monitoring and control of district heating systems. There have been experiments performed with centralized control of substations (Österlind, 1982), however we show that we can achieve distributed concurrent automatic load balancing by the use of agent technology. The experiments described are only initial tests and there is much room for improvements. For instance, because of the flow gauges used, the agents had a limited and delayed view of the environment, resulting in long reaction times. By having continuous readings of consumption we believe that it is possible to better decide the persistence of household heating reductions, which makes it possible to limit unnecessary reductions to household heating. In general, it is also possible to make more informed decisions regarding reductions, e.g., if reduction assistance should be requested from several substations or just a few. Furthermore, it should also be possible to develop strategies to even out the negative effects of reductions over larger areas by manipulating the willingness for agents to cooperate and accept reductions. Future work includes:

- Investigating the scaling effects of the different strategies using a simulation tool (Wernstedt et al., 2003), as well as comparing this and other strategies with centralized control strategies.

- Performing experiments in full-scale district heating systems.

\section{REFERENCES}

ABSINTHE project web site. Retrieved June 21,2004, from http://www.ipd.bth.se/absinthe.
Aringhieri, R., Malucelli, F., 2003. Optimal operations management and network planning of a district heating system with a combined heat and power plant. Annals of Operations Research, 120, 173-199.

Arvastsson, L., 2001. Stochastic modeling and operational optimization in district heating systems, Lund Institute of Technology, Sweden, ISBN 91-628-4855-0.

Bøhm, B., Lucht, M., Park, Y., Sipilä, K., Ha, S., Won-tae, K., Bong-kyun, K., Koljonen, T., Larsen, H., Wigbels, M., Wistbacka, M., 2002. Simple models for operational optimisation, Report 2002:S1, NOVEM. ISBN 90-57-48021-2.

Canu, S., Duran, M., and Ding, X., 1994. District heating forecast using artificial neural networks, International Journal of Engineering, 2(4).

Drysdale, A., Stang, J., 2002. Optimised DH systems using remote heat meter communication and control. In 8th International Symposium on District Heating and Cooling. ISBN 82-594-2341-3.

Gieseler, U., Heidt, F., Bier, W., 2003. Combined thermal measurement and simulation for the detailed analysis of four occupied low-energy buildings. In 8th International IBPSA Conference.

Larsson, G., Rossing, O., 2003. Flödesutjämnande körstrategi (In Swedish). Forskning och Utveckling, FOU 2003:86. ISSN 1402-5191.

Parunak, V., 1996. Applications of Distributed Artificial Intelligence in Industry, in eds. O'Hare , G.M.P., Jennings, N.R., Foundations of distributed Artificial Intelligence. Wiley Inter-Science.

Petersson, S., Werner, S., 2003. Långtidsegenskaper hos lågflödesinjusterade radiatorsystem (In Swedish). Forskning och Utveckling, FOU 2003:88. ISSN 14025191.

Rinaldo, J., Ungar, L., 1998. Auction-driven coordination for plantwide optimization. In FOCAPO'98, Foundations of Computer-Aided Process Operation.

Siemens web site. Retrieved June 21, 2004, from http://www.sbt.siemens.com/press/hvac_pr13.asp.

Swedish Board for Accreditation and Conformity Assessment web site. Retrieved June 21, 2004, from http://www.swedac.se.

Tamminen, E., Wistbacka, M., 2001. Capacity and cost models for thermal power systems with random outages of plants. VTT Energy, Espoo, Research Report ENE6/44/01.

Weiss, G., 1999. Multi-Agent Systems, MIT Press, Cambridge, MA. ISBN 0-262-23203-0.

Wernstedt, F., Davidsson, P., Johansson, C., 2003. Simulation of district heating systems for evaluation of real-time control strategies. In 1st European Simulation and Modelling Conference.

Wooldridge, M., 2002. An introduction to multi-agent systems, John Wiley \& Sons. ISBN 0-471-49691.

Österlind, B., 1982. Effektbegränsning av fjärrvärme (In Swedish). Rapport 63:1982, Byggforskningsrådet. ISBN 91-540-3714. 